\title{
Erratum to: What is the relationship between online activity and driving-licence-holding amongst young adults?
}

\author{
Scott Le Vine $\cdot$ Charilaos Latinopoulos $\cdot$ John Polak
}

Published online: 25 October 2014

(C) Springer Science+Business Media New York 2014

\section{Erratum to: Transportation (2014) 41:1071-1098 DOI 10.1007/s11116-014-9528-3}

We regret noticing a technical failure of character conversion during the typesetting process.

Due to the error an important part of sentence was incorrectly published.

The sentence, part of the Introduction paragraph should have read the following;

The interrelationship between virtual (online) activities and real-world activities is an area of growing interest in recent years. The net effect of internet use on mobility patterns is however ambiguous (Mokhtarian 1990); both negative (substitution) and positive linkages (complementarity) are plausible. Despite the ambiguity regarding the relative magnitude of these countervailing effects, it is frequently suggested that increased online-connectivity has led people to travel less, particularly by car, and perhaps even to feel less need to acquire a driving licence (Alcindor 2012; Buccholz and Buccholz 2012; Kay et al. 2014; Maynard 2014).

The online version of the original article can be found under doi:10.1007/s11116-014-9528-3.

S. Le Vine $(\bowtie) \cdot$ C. Latinopoulos · J. Polak

Department of Civil and Environmental Engineering, Centre for Transport Studies, Imperial College London, Exhibition Road, London SW7 2AZ, UK

e-mail: slevine@imperial.ac.uk

C. Latinopoulos

e-mail: charilaos.latinopoulos10@imperial.ac.uk

J. Polak

e-mail: j.polak@imperial.ac.uk 